\title{
EL VALOR DE MARCA, UNA PERSPECTIVA CENTRADA EN EL CONSUMIDOR DE ALOJAMIENTO
}

\section{BRAND EQUITY, ONE PERSPECTIVE FOCUSED ON THE ACCOMMODATION CONSUMER}

\author{
Diego Salazar Duquel Yessenia Oña Yépez²
}

\section{Resumen}

El presente trabajo es un estudio de revisión sobre el valor de marca desde una perspectiva centrada en el consumidor su objetivo es identificar los factores y dimensiones de medición que se requieren para la construcción del valor de marca con aplicación al sector de alojamiento. Para esta investigación se consideró una metodología de carácter cualitativo a través de documentos y registros bibliográficos elaborados por diversos autores relevantes en el tema, los cuales sirvieron como referente para el desarrollo en el ámbito hotelero. Como resultante, se obtuvieron variables y mediciones adaptables a la construcción de valor de marca que pueden ser útiles para este tipo de organización.

\section{Palabras clave}

Valor de marca, consumidor, alojamiento, marca, hotel.

\section{Abstract}

The present work is a review study about the brand value from a perspective centered on the consumer. Its objective was to determine the factors and dimensions of measurement that are required for the construction of brand value with applicability to the lodgings sector. For this research a methodology of qualitative character was considered through documents and bibliographic records elaborated by diverse relevant authors in the subject, which served as a reference for the development in the hotel sector. As a result, variables and measures adaptable to the construction of brand value that could be useful for this type of organization were obtained.

\section{Keywords}

Brand value, consumer, lodging, brand, hotel.

Clasificación JEL: M11, M30, L84 


\section{Introducción}

Uno de los principales elementos que debe considerar toda empresa, es la construcción o fortalecimiento de una marca sólida o branding (Davis, 2017; Gallart-Camahort, Callarisa y Sánchez, 2019), que le permita alcanzar un posicionamiento y una permanencia en el mercado, como un poderoso instrumento diferenciador entre los productos y las empresas (Escobar 2000; Callarisa et al., 2012; Kotler y Keller, 2016).

Bajo ese escenario, la gestión por parte del empresario deberá ser el diseño e implementación de una imagen de marca o de producto con valor que responda a las necesidades del mercado (Ortegón, 2014). Esto se debe a que la marca es el signo más importante y distintivo con el que un consumidor asocia las características que posee una empresa, sus productos y sus servicios (Aaker, 2002; Kotler y Keller, 2016; Keller, 2016 y 2017; De Oliveira, 2019).

Frente a este escenario, se han generado diversas investigaciones relevantes en torno al valor de marca, donde se plantean diversos factores (variables) y dimensiones que pueden ser consideradas como modelos aplicados en cualquier sector económico. No obstante, muy poco se ha escrito sobre su aplicabilidad en sector de alojamiento lo que dificulta comprender qué componentes pueden aportar significativamente al fortalecimiento de la marca hotelera (De la Oliva, Gallart y Fernández, 2019) o qué criterios pueden ser útiles para el desarrollo de estudios empiricos. En ese sentido, Ponnam y Krishnatray (2008) y González et al. (2011) afirman que siempre ha existido una discrepancia sobre ¿cómo se debe medir el valor de marca? y ¿qué constructos deberían intervenir en su medición?

Por otro lado, el sector de alojamiento, considerado hoy en día como un sistema que enlaza un conjunto de empresas y marcas específicas, compuesto de bienes materiales e intangibles que cobijan, bajo un nombre, a varios establecimientos de alojamiento destinados a proporcionar servicios de hospedaje al público en general (Martínez, 2008) (hoteles, hosterías, cabañas, residenciales, haciendas o estancias, lodges, apart-hoteles, entre otros) pueden llegar a ser organizaciones insignia de un destino turístico (Bigné et al., 2000; Jiménez, 2008; Flecha, 2014), los cuales deben generar valor, y ofrecer, al huésped, productos y servicios que sean deseables con características o funcionalidades únicas o distintas a las que los competidores ofrecen.

Kotler y Armstrong (2012) consideran que aquellas marcas que ganan un espacio en el mercado no lo hacen solo por entregar un beneficio tangible o intangible, sino porque establecen conexiones profundas con los clientes (Aaker, 2002; Siabato y Duque, 2014). Es por ello indispensable identificar qué componentes se encuentran relacionados significativamente con la construcción de una marca.

Con base a este contexto, el objetivo de este trabajo es identificar los factores y dimensiones para la creación de valor de marca hotelera, desde una perspectiva centrada en el consumidor mediante una investigación de revisión bibliográfica, a partir de las aportaciones de autores referentes al objeto de estudio. El resultado que se obtenga de este estudio permitirá tener una base conceptual para el desarrollo de futuras investigaciones empíricas a nivel académico como componentes claves para el desarrollo estratégico y operativo a nivel empresarial (Bassat, 2016).

\section{Metodología}

Con el fin de identificar aquellos factores y dimensiones necesarios para la construcción del valor de marca para el sector de alo- 
jamiento, se considera un estudio metodológico de carácter bibliográfico con relevancia en las aportaciones documentales generadas hasta la fecha mediante un análisis bibliométrico Bellavista et al., (1997) referidos por Rodríguez et al., (2017). En este proceso se consideró trabajar a partir de varios indicadores de publicación y citación definidos por fases: 1) identificación de las palabras clave, descriptores o términos formulados en el estudio, 2) revisión de los aportes literarios que hacen referencia al estudio mediante la revisión del contenido de cada documento en temáticas orientadas a nivel administrativo, servicios y aojamiento y 3) pertinencia, estructuración y relación entre los distintos descriptores (factores y variables).

Para la primera fase, se consideró trabajar con 7 palabras clave tanto en inglés como en español: valor de marca, consumidor, alojamiento, marca, hotel en el contexto latinoamericano, sector de servicios y destinos turísticos.

Posteriormente, para la segunda fase, se revisaron diversas bases de datos o fuentes secundarias como: bibliotecas privadas, públicas y virtuales, Google Académico y revistas indexadas publicadas desde 1990 hasta principios del 2019. Aquí se identificaron distintas posturas teóricas, conceptuales o empíricas consideradas por varios autores como: Martin y Brown (1990), Lassar et al. (1995), Aaker (1996), Yoo et al. (2000), Colmenares y Saavedra (2007), Funes-Funes (2014), Levario y Campos (2018), entre otros; que abordan temáticas relacionadas con el valor de marca que se orientan a estudios de administración y específicamente del sector de servicio o de alojamiento.

Para ello, en esta fase, se consideraron: primero bases de datos según: la disponibilidad, accesibilidad, calidad y pertinencia en la información; segundo, los artículos que fueron analizadas, en su mayoría, se encuentran en revistas con una categoría muy po- sicionada como: Escuela de Administración de Negocios, Revista Europea de Dirección y Economía de la Empresa, Pasos, Revista de Turismo y Patrimonio Cultural, Cuadernos de Gestión, Cuadernos de Estudios Empresariales, Gran Tour: Revista de Investigaciones Turísticas, Consumer Marketing (indexadas en SCOPUS de Elsevier, RedALyC -Red de Revistas Científicas de América Latina y del Caribe, SciELO -Scientific Electronic Library Online, Latindex, SSCI, SC, ISI, EBSCO, Elsevier, Genamics Journal Seek, Directory of Open Access Journals -DOAJ, entre otros).

Como resultado, se identificaron 17 publicaciones (100\%) que contribuyen y abordan la temática planteada en este estudio, de igual forma se resaltaron, por su aplicabilidad, pertinencia en el contexto formulado, o por el número de veces que han sido citadas como referentes para otras aportaciones (2 tesis, 2 libros y 13 artículos científicos). Aquí se observa que no existen estudios descriptivos actuales sobre el valor de marca a nivel hotelero, a excepción de Casanovas y Santandreu quien desarrolla sus estudios en 2009 donde aborda superficialmente este objeto de estudio. Según la información que presenta Google Académico, 6 investigaciones principales (35.2\%): Aaker (2002), Thomson (2005), Casanovas y Santandreu (2009), Buil et al. (2010), Buil et al. (2013), y González (2011) generan aportes a nivel académico en materias de administración, marketing, hospitalidad y servicio, dentro de las ciencias sociales donde el número de citaciones que poseen son: 761, 300, 3, 91, 41, y 67 respectivamente.

Finalmente, como tercera fase, una vez identificadas las publicaciones existentes, se identificaron y arroparon las variables consideradas por cada autor para la construcción de valor de marca, mediante el número de veces que los factores (16) y dimensiones (69) han sido considerados, mencionados o establecidos (Tabla 1). 


\section{Desarrollo}

\section{La marca}

Concebida como un factor determinante, diferencial, inimitable y activo intangible, una marca puede crear y agregar valor a las empresas, productos y servicios (Escobar, 2000; Siabato y Duque, 2014; Berrozpe, 2015); este a su vez puede ser un nombre, término, letrero, símbolo y diseño, o la combinación de estos elementos como identificar y diferenciador de productos o servicios de una organización ante sus competidores (Kotler y Armstrong, 2012). Para su construcción, es necesario tener ciertas consideraciones como: posicionamiento de marca, selección del nombre de marca, patrocinio de marca y desarrollo de la marca (Aaker, 2002; Kotler y Armstrong, 2012).

Dependiendo de las estrategias comerciales que haya considerado una empresa, un consumidor podrá evaluar la relación que se genera entre el producto-servicio y el precio según la marca, y así disminuir una compra basada entre la materia primacosto de producción-costo de distribución y su precio. Según Del Río Lanza et al. (2002), el consumidor reacciona primero a la marca y es muy probable que no le interesen ciertos activos tangibles que posea la empresa como sus instalaciones o sus equipos.

\section{El valor de marca}

El valor de marca es considerado como un efecto diferenciador positivo que tiene una organización como respuesta del cliente ante un producto o servicio (Kotler y Armstrong, 2012). De acuerdo con los conceptos identificados por Del Río et al. (2002) o Siabato y Duque (2014), se tiene una idea más clara a nivel general sobre las diversas conceptualizaciones que se han desarrollado en torno a este contexto.
Según Smith (1991), referido por Del Río et al. (2002), por ejemplo, el valor de una marca es considerado como un valor monetario que se deriva del grado en que el nombre de marca favorece a las transacciones o intercambios que puedan existir entre la empresa con sus clientes.

Para Aaker (1991), este contexto es una entidad multidimensional formada por cinco componentes: lealtad a la marca, notoriedad, calidad percibida, asociaciones de la marca y otros activos vinculados a la marca como las patentes.

Por su parte Keller $(1993,1998)$, citado por Del Río et al. (2002), considera que el valor de marca es un efecto diferencial que ejerce el conocimiento del nombre de marca sobre su respuesta a las acciones de Marketing.

\section{Enfoques del valor de marca}

Según Del Río Lanza et al. (2002), el valor de marca parte de tres principales perspectivas: financiera, consumidor y por su naturaleza global. De los conceptos presentados anteriormente, el aporte referido de Smith (1991, 1996) se genera sobre la base financiera, el de Aaker sobre la base de la perspectiva global, y el de Keller $(1993,1998)$ sobre la perspectiva del consumidor (Del Río Lanza et al., 2002; Aaker, 2002). Buil et al. (2010), González et al. (2011) y Siabato y Duque (2014), por su parte, consideran la existencia de solo dos enfoques para medir el valor de marca: el financiero y del consumidor.

Desde la perspectiva financiera, Del Río Lanza et al. (2002) resaltan las aportaciones de Stobart (1989), Tauber (1989), Smith (1991) y Simon y Sullivan (1993), quienes enfatizan el papel de la marca como un activo intangible más que posee la empresa, el cual puede afectar a los flujos de caja de la empresa, al valor de sus acciones o a su precio de venta. Este enfoque se centra en los beneficios o resultados monetarios que 
la marca puede aportar a las organizaciones (Buil et al., 2010).

Dentro del sector de alojamiento, dar un valor de marca desde una perspectiva financiera involucra dar un servicio eficaz y rápido; esto requiere incorporar un sistema tecnológico hotelero como es el caso de: Zeus, software PMS (Property Managment System), TIC (Tecnologías de la Información y la Comunicación) o Channel Manager; como programas diseñados para optimizar adecuadamente la gestión hotelera desde las reservas hasta los procesos de check out; esto reduce significativamente errores de carga, sobreventas y ahorro de tiempo.

Desde una perspectiva global, se considera a la marca como la relación existente entre las actitudes y conductas de la empresa, los consumidores, los distribuidores y los mercados financieros (Del Río Lanza et al., 2002).

Los hoteles o cadenas hoteleras deben renovar constantemente la habilidad para integrar, construir y reconfigurar sus competencias internas y externas para adecuarse a entornos cambiantes (Teece et al., 1997) y adaptarse rápida y eficazmente a los cambios de los mercados; esto evitar la obsolescencia y la pérdida de competitividad. Con base en la perspectiva centrada en el consumidor, Del Río Lanza et al. (2002) consideran a la marca como una ventaja competitiva que aporta valor a la empresa y al consumidor (Navas, 2015); un efecto diferenciador que provoca el conocimiento de la marca sobre los consumidores (Keller, 1993; De La Martinière et al., 2008; Kotler y Keller, 2016).

En este punto, hay que resaltar el aporte de Siabato y Duque (2014) quienes identifican y analizan distintos modelos del valor de marca según su enfoque, los cuales tienen como función principal medir o diagnosticar el capital de marca (Navas, 2015; Villarroel et al., 2018) o proyectar la intervención o construcción para la gestión de la marca (branding).
La importancia que tiene este enfoque dentro del sector hotelero es fundamental, puesto que el consumidor/huésped es con quien se tiene contacto directo todo el tiempo.

\section{Factores y dimensiones de medición del valor de marca}

David Aaker, en 1991, consideró criterios como: lealtad de marca, conocimiento de marca, calidad percibida, asociaciones de marca, y otros activos de marca (patentes, marcas comerciales, canales, relaciones, entre otros); posteriormente, consideró diez dimensiones o componentes clave para medir el valor de la marca: el precio o sobreprecio, satisfacción del cliente-fidelidad, calidad percibida, liderazgo/popularidad, valor de uso, personalidad, reconocimiento de marca, organización, participación de mercado e índices de precios y distribución (Vera, 2008 y Herrera y Quezada, 2011).

Keller (1993) considera la medición del valor de marca a través de las dimensiones que integran el conocimiento de la enseñanza: notoriedad de la marca y asociaciones unidas a ella (Buil et al., 2010).

Siabato y Duque (2014) concideran un conjunto de cualidades asociadas al nombre y los símbolos que la conforman: conciencia del nombre de marca, calidad percibida, asociaciones de marca y lealtad de marca (Aaker D. , 1991).

González et al. (2011) y Siabato y Duque (2014) estiman una serie de factores sobre la base del modelo customer-based brand equity: análisis del conocimiento de marca, actitud hacia la marca y relación con la marca.

Chen (2010) y Herrera y Quezada (2011) miden componentes del valor de marca sobre el green marketing: valor de marca verde, confianza verde, satisfacción e imagen verdes.

Bigné et al. (2013) plantean tres dimensiones: calidad percibida de la tienda, lealtad a la tienda, y notoriedad/asociaciones del establecimiento. 
Campano y Aguirre (2015) realizan una medición de valor de marca sobre la base de seis dimensiones: lealtad afectiva-comportamental, lealtad cognitiva, asociaciones de marca, calidad percibida, reconocimiento de marca y recordación de marca.

Barreiro et al. (2001) desarrollan un estudio de valor o imagen de marca de productos lácteos donde evalúa: calidad percibida con base en la cata hedónica y calidad real con base en la cata analítica.

Otros autores consideran otros criterios formulados sobre la base de David Aaker
(1991) para la construcción y medición del valor de marca (ver tabla 1).

\section{Criterios y escalas de medición según las variables de construcción del valor de marca}

Una vez identificados los factores determinantes para la construcción del valor de marca, es necesario considerar las dimensiones o escalas de medición correspondientes a cada una de ellas. La tabla 1 muestra aquellas medidas 0 escalas consideradas por los diversos autores.

Tabla l. Factores y dimensiones de medida aplicados al valor de marca

\begin{tabular}{|c|c|}
\hline Factores & Dimensiones \\
\hline Lealtad de marca & $\begin{array}{l}\text { - Lealtad global. } \\
\text { - Recomendación. } \\
\text { - Comportamiento y actitud ante la compra. } \\
\text { - Consumidores leales. } \\
\text { - Cuota de mercado absoluta y relativa, elasticidad cuota-precio directa y cruzada. } \\
\text { - Disponibilidad de la marca. } \\
\text { - Disposición a pagar un sobreprecio. } \\
\text { - Opciones de compra. } \\
\text { - Grado de compromiso. } \\
\text { - Nivel de recompra. } \\
\text { - Precio primado. }\end{array}$ \\
\hline $\begin{array}{l}\text { Asociaciones de } \\
\text { marca/Relación } \\
\text { con la marca }\end{array}$ & $\begin{array}{l}\text { - Imágenes, pensamientos, experiencias, sentimientos, percepciones, creencias, actitudes. } \\
\text { - Valor percibido, personalidad de la marca, asociaciones organizacionales. } \\
\text { - Identificación espontánea de atributos asociados. } \\
\text { - Grado de satisfacción de los atributos asociados. } \\
\text { - Personalidad de marca. }\end{array}$ \\
\hline Calidad percibida & $\begin{array}{l}\text { - Valoración de las habitaciones, ubicación y limpieza. } \\
\text { - Calidad del producto, servicio y marca percibido. } \\
\text { - Características. } \\
\text { - Confianza-nivel de confiabilidad. } \\
\text { - Consistencia-nivel de satisfacción. } \\
\text { - Rendimiento percibido, capacidad de respuesta. } \\
\text { - Grado de seguridad. } \\
\text { - Nivel de empatía. } \\
\text { - Nivel de liderazgo. }\end{array}$ \\
\hline $\begin{array}{l}\text { Conocimiento, } \\
\text { reconocimiento, } \\
\text { notoriedad o } \\
\text { conciencia de } \\
\text { marca }\end{array}$ & $\begin{array}{l}\text { - Utilidad del comentario realizado para otros internautas y la cantidad de visitas generadas } \\
\text { en redes. } \\
\text { - Conocimiento de marca. } \\
\text { - La familiaridad existente de la marca. } \\
\text { - Primera marca mencionada y reconocimiento de la marca. } \\
\text { - Reconocimiento de la marca. } \\
\text { - Recuerdo espontáneo y sugerido. } \\
\text { - Conocimiento de publicidad. } \\
\text { - Tipo de medio publicitario recordado. }\end{array}$ \\
\hline
\end{tabular}




\begin{tabular}{|c|c|}
\hline Otros activos & - Innovación, patentes, marcas registradas, ratio. \\
\hline $\begin{array}{l}\text { Actitud hacia la } \\
\text { marca }\end{array}$ & $\begin{array}{l}\text { - Afecto hacia la marca. } \\
\text { - Calidad percibida de la marca. } \\
\text { - Cariño hacia la marca. } \\
\text { - Diferencia existente entre marcas. } \\
\text { - Necesidad versus compra. } \\
\text { - Porcentaje de consumidores con intención de comprar la marca. }\end{array}$ \\
\hline $\begin{array}{l}\text { Intención de } \\
\text { compra }\end{array}$ & - La disposición a comprar la marca. \\
\hline $\begin{array}{l}\text { Valor percibido/ } \\
\text { Valor de uso }\end{array}$ & $\begin{array}{l}\text { - Relación calidad precio, análisis conjunto. } \\
\text { - Comparación entre marcas. } \\
\text { - Precio adecuado. } \\
\text { - Relación calidad-precio. } \\
\text { - Relación de pago sobre el precios altos o bajos. }\end{array}$ \\
\hline Imagen de marca & $\begin{array}{l}\text { - Valoración del servicio ofrecido en recepción. } \\
\text { - Elementos, situaciones, atributos, cualidades, símbolos. } \\
\text { - Evaluación general de la marca. } \\
\text { - Mapas de imagen. } \\
\text { - Opinión de la marca. } \\
\text { - Reputación de la marca. } \\
\text { - Sinceridad, excitación, competencia, sofisticación, rudeza. } \\
\text { - Valor percibido, personalidad, organización. }\end{array}$ \\
\hline $\begin{array}{l}\text { Precio superior o } \\
\text { sobreprecio }\end{array}$ & $\begin{array}{l}\text { - Lo que el cliente está dispuesto a pagar por una marca, a diferencia de lo que pagaría por } \\
\text { otra. }\end{array}$ \\
\hline $\begin{array}{l}\text { Satisfacción del } \\
\text { cliente }\end{array}$ & $\begin{array}{l}\text { - Grado de lealtad expresada hacia la marca por parte del consumidor. } \\
\text { - Número de clientes actuales. } \\
\text { - Satisfacción con su marca actual. }\end{array}$ \\
\hline $\begin{array}{l}\text { Liderazgo / } \\
\text { popularidad }\end{array}$ & $\begin{array}{l}\text { - Actitud hacia lo innovador que el consumidor percibe de una marca independientemente } \\
\text { de la calidad. }\end{array}$ \\
\hline $\begin{array}{l}\text { Personalidad de } \\
\text { la marca }\end{array}$ & $\begin{array}{l}\text { - Beneficios simbólicos y emocionales suministrados por la marca. } \\
\text { - Existencia de personalidad. } \\
\text { - Imagen del tipo de personas que consumen la marca. } \\
\text { - Interés de la marca. }\end{array}$ \\
\hline Organización & $\begin{array}{l}\text { - Confianza de la empresa fabricante. } \\
\text { - Credibilidad de la empresa fabricante. } \\
\text { - Gusto de la empresa fabricante. } \\
\text { - Percepción de la compañía con la que se asocia la marca. }\end{array}$ \\
\hline $\begin{array}{l}\text { Participación del } \\
\text { mercado }\end{array}$ & - Rendimiento de la marca entendida como su participación de mercado o volumen de ventas. \\
\hline $\begin{array}{l}\text { Índice de precios } \\
\text { y distribución }\end{array}$ & $\begin{array}{l}\text { - Valor de la marca al que se cotiza en el mercado. Precio o valor financiero de la marca per- } \\
\text { cibido por inversionistas y accionistas. }\end{array}$ \\
\hline
\end{tabular}

Fuente: sobre la base de: Martin y Brown (1990), Lassar et al. (1995), Innscher (1993), y Francois y MacLachlan (1995) en Villarejo (2002); García y Bergantiños (2001) en Martínez et al. (2005); Thompson (2005); Colmenares y Saavedra (2007); Vera (2008); Yoo et al. (2000); Aaker (1996), Netemeyer et al. (2004), y Pappu et al. (2005, 2006) en: Buil et al. (2010); González et al. (2011); Kotler y Keller (2012); Rodríguez y Brown (2012); Callarisa et al. (2012); Funes-Funes (2014); Ortegón (2014); Castillo y Ortegón (2014), Salazar, Quintero y Mena (2016), Kladou et al., 2017; Levario y Campos (2018). 


\section{Relación factorial y dimensional}

Entre los factores que sobresalen se encuentran: lealtad de marca, asociaciones/ relación de marca, calidad percibida, y notoriedad, conciencia o conocimiento de marca; se resaltan también variables como: actitud ante la marca, valor percibido, imagen de marca y satisfacción del cliente. Se suman aquellas que muy poco han sido apreciadas como: intención de compra, precio, liderazgo o popularidad.

Lealtad de marca. Considerado como el apego afectivo que siente el cliente por la marca producto del nivel de satisfacción resultante de las experiencias pasadas. Esta actitud se desarrolla cuando un consumidor realiza una compra a la misma marca o frecuenta el mismo establecimiento (Ildefonso, 2012; González et al., 2011). En el sector de alojamiento, el proceso de generar lealtad puede perderse cuando la compra o selección de un establecimiento hotelero es B2B y el proceso es realizado por terceros, evitando así el contacto directo con el cliente. La lealtad hotelera puede ser medida por elementos clave como: facilidades, placer, comodidades, disfrute y experiencia, las cuales tienen que ver con la personalización, identidad, afinidad y servicio excelente de forma excepcional y no robotizada (Veloutsou, 2015).

Asociación de marca. Representa la base para la decisión de compra y para la lealtad a la marca (Aaker, 1991, y Siabato y Duque, 2014). Entre los aspectos manifestados por Kotler y Keller (2016) se encuentran: imágenes, pensamientos, experiencias, sentimientos, percepciones, creencias y actitudes. El desarrollo de la asociación de marca es un vínculo existente al recuerdo mediante la percepción (Saavedra, 2004), la cual puede o no reflejar una realidad objetiva de los productos que posee una empresa (Jiménez-Zarco et al., 2004; Lieven y Hildebrand, 2016). Díaz y Chavez (2015) consideran que desarrollar un valor de marca ciudad se verá influenciado por las diversas marcas productos que se ofrecen dentro de ella e involucra diversas organizaciones que contribuyen a alcanzar sus objetivos (Andrade, 2016). De acuerdo con los estudios de González et al. (2011) este elemento se desarrolla por las experiencias previas que se hayan generado entre los clientes y las marcas después de una compra e influyen favorablemente en la próxima decisión. Para el sector de alojamiento, este criterio es relevante por la amplia oferta existente: desde hoteles que pertenecen a reconocidas cadenas hasta hoteles independientes, los cuales ofrecen propuestas innovadoras asociadas con un servicio personalizado.

Calidad de marca percibida. Hace referencia a la percepción que posee un consumidor sobre la calidad de un producto respecto a su propósito (Zeithaml, 1988; Zeithaml et al., 2009; Callarisa et al., 2012) (resultado después de la compra); se considera como un referente a las alternativas que pueden existir de la competencia (Aaker, 1991; López, 2017). Callarisa et al. (2012) reafirman la existencia de siete elementos para medir la calidad del producto: rendimiento, características, calidad de sus componentes, fiabilidad, durabilidad, utilidad, diseño y estilo. Para Funes-Funes (2014) la opinión que el usuario tiene sobre la ubicación del hotel, las habitaciones y la limpieza son aspectos influyentes. El huésped exige hoy en día instalaciones automatizadas, innovadoras y tecnológicas (Solsona, 2018).

Conocimiento, notoriedad o conciencia de marca. este elemento hace referencia a la capacidad que puede tener una marca en un individuo al ser recordada o reconocida (notoria) por sus principales signos (nombre, símbolo, logotipo) (Aaker, 1991, González et al., 2011; Siabato y Duque, 2014, López, 2017; Funes-Funes, 2014). El conocimiento hotelero puede ser medido a 
partir de: seguimientos, comentarios y observaciones que los huéspedes desarrollan sobre una marca (engagement) (Callarisa et al., 2012).

Otros activos de marca. existen otros aspectos que contribuyen a fortalecer el valor de marca, estos pueden encontrarse en las patentes o las marcas registradas (Aaker, 1991; Casanovas y Santandreu, 2009). Una forma para valorar económicamente una marca o patente puede ser por el método de valoración económica de marca ISO 10668, el Método Royalties (Royalty Relief Method), método de Flujos de Caja descontados (Discounted Cash Flow Method), entre otros (Jiménez, 2013; Cerviño y Baena, 2014; RubioMartín y Rodríguez, 2016). Este criterio tiene relación con la valoración de marca desde la perspectiva financiera que dé el consumidor. Según algunas leyes, es necesario cumplir de forma obligatoria ciertos requisitos para obtener permisos de funcionamiento de los establecimientos de alojamiento a nivel nacional (Registro Oficial Suplemento 465, 2016).

Actitud hacia la marca. Se considera como una percepción subjetiva de la marca que surge a partir del valor que cada consumidor le otorga al producto o servicio según su propio juicio crítico, producto de factores externos o internos que influyen en la decisión de compra: estímulos de marketing mix, economía, tecnología, cultura, entre otros (Kotler y Armstrong, 2012). Este elemento se mide a través de varios componentes: beneficios percibidos, atributos asociados a la marca y personalidad atribuida a una marca. Según González et al. (2011) el mercado está influenciado por la publicidad del hotel y la promoción de ventas que se realizan dentro o fuera del establecimiento hotelero.

Valor percibido de la marca. Se considera a este criterio como una función de la calidad percibida por el cliente en relación con el precio pagado, el cual se genera según las preferencias de los compradores
(Zeithaml, 1988; Callarisa et al., 2012; Kotler y Keller, 2016; Funes-Funes, 2014) y el beneficio total (Kotler y Keller, 2016). Según Yoo et al. (2000), el precio es un componente clave que se vincula con el valor de marca (Villarejo, 2002). Para el sector de alojamiento existen ciertos criterios que influyen en el valor percibido, los que pueden variar según la disponibilidad y necesidad del huésped. Las categorías hoteleras constituyen un primer indicador que permite ubicar a un hotel concreto dentro de un determinado estrato de la oferta y formar diversas expectativas referentes al precio establecido, tanto de los servicios que previsiblemente se obtendrán como del precio que se va a pagar. Para no generar una confusión durante su aplicabilidad, este criterio debería ser considerado como parte de la calidad de marca percibida.

Intención de compra. González et al. (2011) consideran este como factor cognitivo y afectivo que se genera en el consumidor e influye en el proceso de compra. Existe una gran posibilidad de que el consumidor prefiera un producto o servicio de entre los posibles competidores; esto ocurre cuando en la mente de los clientes el producto tiene un valor elevado. Para el sector de alojamiento, las instalaciones, las habitaciones, el ambiente del establecimiento hotelero, son valores agregados al proceso de compra que incide en la percepción de la calidad-costo.

Imagen de marca. Kotler y Keller (2016) hacen referencia a las propiedades extrínsecas que posee un producto o servicio y constituyen un elemento intangible que posee un valor capital. De acuerdo con Martínez et al. (2005) la imagen de marca es un conjunto de significados que la gente describe, recuerda y relaciona con algo. La imagen de un destino turístico, por ejemplo, se lo define como la percepción global que un individuo o grupo de individuos poseen, la cual es determinada por el conocimiento que se tiene sobre sus atributos, las impresiones 
y sentimientos (Bigné et al., 2000; Boubeta et al., 2008; Gutiérrez et al., 2010, Andrade, 2016). En este sentido, las organizaciones deben cuidar la imagen considerando tres puntos de vista: imagen percibida, imagen real e imagen deseada. Para el sector de alojamiento, la imagen representa la percepción de la organización, así como sus productos y servicios (García et al., 2018); un elemento de gran relevancia para el éxito de la empresa (Cabral, 2017). Para medirla será necesario evaluar los resultados: cognitivos (aprender/información retenida), afectivos (sentir) y conductuales (hacer-compra, poscompra, recompra).

\section{Propuesta}

Sobre la base de lo mencionado anteriormente, se pueden considerar, para futuras investigaciones empíricas, los siguientes factores y dimensiones (ver tabla 2) como modelo para la construcción de valor de marca para el sector de alojamiento.

Tabla 2. Factores y dimensiones para la construcción de valor de marca aplicados al sector de alojamiento

\begin{tabular}{|c|c|}
\hline Factor & Dimensión \\
\hline Conocimiento marca & $\begin{array}{l}\text { - Conocimiento y reconocimiento de la marca. } \\
\text { - Elementos publicitarios recordados. } \\
\text { - Comentarios referentes a la marca en redes sociales. }\end{array}$ \\
\hline Imagen de marca & $\begin{array}{l}\text { - Identidad corporativa intangible. } \\
\text { - Identidad corporativa visual. } \\
\text { - Imagen corporativa. } \\
\text { - Diseño y elementos de imagen. } \\
\text { - Atributos de la imagen. } \\
\text { - Cualidades de la imagen. } \\
\text { - Símbolos o imagen (percibida, real, deseada). }\end{array}$ \\
\hline Asociaciones de marca & $\begin{array}{l}\text { - Imágenes. } \\
\text { - Pensamientos. } \\
\text { - Experiencias. } \\
\text { - Sentimientos. } \\
\text { - Percepciones. } \\
\text { - Creencias. } \\
\text { - Actitudes. }\end{array}$ \\
\hline Actitud hacia la marca & $\begin{array}{l}\text { - Afecto hacia la marca. } \\
\text { - Necesidad de compra. } \\
\text { - Cultura del consumidor. }\end{array}$ \\
\hline $\begin{array}{l}\text { Calidad de marca } \\
\text { percibida }\end{array}$ & $\begin{array}{l}\text { - Nivel de satisfacción sobre la valoración de los porductos y servicios: (habitaciones, } \\
\text { la ubicación, la limpieza, procesos de recepción, comida, entre otros productos y ser- } \\
\text { vicios que oferte la organización). }\end{array}$ \\
\hline Activos registrados $(*)$ & - Patentes de marca o productos registrados. \\
\hline Lealtad de marca (*) & $\begin{array}{l}\text { - Cuota de mercado. } \\
\text { - Nivel de recompra. } \\
\text { - Grado de compromiso (engagement). }\end{array}$ \\
\hline
\end{tabular}

Fuente: elaboración propia 
Sobre la base de estos indicadores identificados, esta propuesta, permite a los investigadores tener una guía bibliográfica para el desarrollo de futuras investigaciones, las cuales podrán ser validadas a través del estudio.

\section{Discusión}

Gracias a los aportes de Aaker (1991) se pueden considerar ciertos factores claves para la creación de valor de marca, la cual permite sostenerse en el tiempo. Lo mismo pasa con las contribuciones de Garolera (1997); Del Río Lanza et al. (2002); Lee y Back (2008); Vera (2008); Buil et al. (2010), entre otros. No obstante, por la gran diversidad de estudios sobre el valor de marca han generado una variedad de criterios que pueden influir en la construcción de valor de marca.

Por otro lado, aquellas investigaciones que aportan un sustento teórico se presentan desde una perspectiva generalizada a cualquier tipo de organización. Aquellas investigaciones específicas, desarrolladas para diversos campos del conocimiento, toman como base la contribución de los autores mencionados con anterioridad; no obstante, se han dado cuenta que sus criterios no se relacionan con su propia realidad lo que ha llevado a adaptar las medidas a partir de sus necesidades.

De la bibliografía consultada, se puede observar que existe una disminución investigativa sobre nuevos modelos para la creación del valor de marca, desde la óptica del consumidor, posterior a la primera década del siglo XXI; los trabajos iniciales sobre la base de los modelos existentes son de finales del siglo XX. Esto quiere decir dos cosas: o los cimientos presentados por los primeros exponentes son válidos en su aplicabilidad en la actualidad para crear valor de marca o no han sido evaluados a partir de la nueva realidad en la que viven las empresas hoy en día. Actualmente, existen nuevos comportamientos por parte de los consumidores al momento de elegir una marca, producto o servicio que deberían ser considerados.

No existe la cantidad suficiente de estudios empíricos que validen criterios de medición referente al valor de marca en el sector de alojamiento y no son suficientes para contrastar su aplicabilidad; si bien aún no se han validado las medias identificadas en este estudio, podrían preliminarmente contribuir a la construcción de valor de marca en las diversas organizaciones del sector de alojamiento.

\section{Conclusiones}

Con base en las distintas contribuciones existentes presentadas por varios autores, se puede manifestar que la conceptualización del valor de marca depende del enfoque que se desee estudiar: desde una perspectiva financiera o del consumidor.

La marca hotelera es un elemento diferenciador de la competencia que permite establecer una determinada posición en la mente de los consumidores, clientes o huéspedes actuales y potenciales. Su función será proporcionar, de forma consistente, un conjunto de elementos, características, beneficios y servicios sobre la marca que se impregnen en cada visita que se realiza.

La mejor forma de medir el valor de marca es considerar diferentes escalas dimensionales (multidimensional) que contemplen todos aquellos factores que influyen en el consumidor al momento de tomar una decisión sobre una empresa, producto o servicio.

Se propone como modelo, un total de 7 factores compuesto por 22 dimensiones: conocimiento marca (3 dimensiones), imagen de marca (7), asociaciones de marca (7), actitud hacia la marca (3), calidad de marca percibida (1), activos registrados (1), y lealtad de marca (3), los cuales deben ser validados, en futuras 
investigaciones, mediante estudios empíricos para medir la efectividad del constructo.

Para futuros estudios, es recomendable también analizar exhaustivamente los efectos motivadores de los clientes para optar por una u otra cadena hotelera en una sociedad en continuo cambio y con nuevos valores. Con esto, se podría evaluar la relación con el comportamiento del consumidor para generar modelos incluyentes entre el valor de marca y aquellos factores externos e internos que influyen en la decisión de compra que genere mayor significancia al estudio abordado.

\section{Bibliografía}

Ortegón, L. (2014). Gestión de marca. Conceptualización, diseño, registro, construcción y evaluación. Bogotá: Politécnico Grancolombiano.

Martínez, H. (2008). Diccionario de Hospitalidad. Quito: Gráfica Cobos.

Jiménez Martínez, A. d. (2008). Las cadenas hoteleras en el mundo y evolución de su operación en México al inicio del siglo XXI. Innovar, 18(32), 167 - 194.

Flecha, M. D. (2014). Estudio sobre la distribución en las cadenas hoteleras españolas: análisis empírico de su repercusión en la rentabilidad de los hoteles (Tesis Doctoral). Madrid: Universidad Rey Juan Carlos.

Escobar Naranjo, S. (2000). La equidad de marca" Brand Equity" una estrategia para crear y agregar valor. Estudios Gerenciales, 16(75), 35-41.

Siabato, M. F., \& Duque, E. (2014). Evolución y caracterización de los modelos de Brand Equity. Suma de negocios, 5(12), 158-168.

De La Martinière, M., Damacena, C., \& Hernani, M. (2008). Medición y determinantes del valor de marca en la perspectiva del consumidor. Contabilidad y negocios, 3(6), 19 -37.

Buil, I., Martínez, E., \& De Chernatony, L. (2010). Medición del valor de marca desde un enfoque formativo. Cuadernos de gestión, 10, 167-196.
Del Río Lanza, A., Vázquez, Rodolfo, \& Iglesias, V. (2002). El valor de marca: perspectivas de análisis y criterios de estimación. Cuadernos de Gestión, 1(2), 87 -102.

Aaker, D. (1991). Managing brand equity. Capitalizing on the Value of a Brand Name. New York: The Free Press.

Callarisa, L., Sánchez, J., Moliner, M., \& Forgas, S. (2012). La importancia de las comunidades virtuales para el análisis del valor de marca. El caso de Tripadvisor en Hong Kong y París. Papers de turisme, 52, 89-115.

González, E., Orozco, M., \& de la Paz, A. (2011). El valor de la marca desde la perspectiva del consumidor. Estudio empírico sobre preferencia, lealtad experiencia de marca en procesos de alto bajo involucramiento de compra. Contaduría y Administración, 235, 217-239.

Salazar, D., Quintero, J., \& Mena, F. (2016). Criterios de medición en la lealtad del cliente aplicados a restaurantes de la ciudad de Quito. Gran Tour: Revista de Investigaciones Turísticas, 14, 23 - 43.

Kotler, P., \& Keller, K. (2012). Dirección de marketing (Vol. decimocuarta edición). México: Pearson Educación.

Ildefonso, E. (2012). Marketing de los servicios (4a. ed.). Madrid: ESIC Editorial.

Saavedra, J. (2004). Capital de Marca desde la Perspectiva del Consumidor. Revista Venezolana de Gerencia, 9(27), 508 - 528.

Ponnam, A., \& Krishnatray, P. (2008). Rethinking branding: the need for a new conceptual framework to analyze customer-based brand equity. Journal of Brand Management, 5(2), 31-38.

Funes-Funes, C. (2014). Valoración de la marca de los hoteles de la ciudad de Jaén (Tesis de Grado). Universidad de Jaén. Facultad de Ciencias Sociales y Jurídicas.

Villarejo, Á. (2002). Modelos multidimensionales para la medición del valor de marca. Investigaciones Europeas en Dirección y Economía de la Empresa, 8(3), 13-44.

Zeithaml, V. (1988). Consumer perceptions of price, quality, and value: a means-end model and synthesis of evidence. The Journal of marketing, 52(3), 2-22. 
Zarco, A. I., \& et al. (2004). Dirección de productos y marcas. Barcelona: Editorial UOC.

Vera Martínez, J. (2008). Perfil de valor de marca y la medición de sus componentes. Academia. Revista Latinoamericana de Administración, 41, 70 - 89.

Álvarez, A. (2007). Análisis de los activos del valor de marca turística: diferenciación, gestión de imagen, calidad percibida, fidelización, el marketing de viva voz y la comunicación integrada. Anuario jurídico y económico escurialense, 40, 591-630.

Keller, K. (1993). Conceptualizing, Measuring, and Managing Customer-Based Brand Equity. The Journal of Marketing, 1, 1- 22.

Yoo, B., Donthu, N., \& Lee, S. (2000). An examination of selected marketing mix elements and brand equity. Journal of the academy of marketing science, 28(2), 195-211.

Lee, J.-S., \& Back, K.-J. (2008). Attendee-based brand equity. Tourism Management, 29(2), 331-344.

Buil, I., De Chernatony, L., \& Martínez, E. (2013). La importancia de medir el valor de marca desde la perspectiva del consumidor: Evidencia empírica en España y el Reino Unido. Revista de Ciencias Sociales, 19(2), 226 - 237.

Pappu, R., Quester, P., \& Cooksey, R. (2005). Consumer-based brand equity: improving the measurement-empirical evidence. Journal of Product \& Brand Management, 14(3), 143-154.

Bigné, E., Font, X., \& Andreu, L. (2000). Marketing de Destinos Turísticos: análisis y estrategias de desarrollo. Madrid: ESIC.

Aaker, D. A. (2002). Construir marcas poderosas. Barcelona: Gestión 2000.

Herrera, D., \& Quezada, G. (2011). Valor de marca verde y su relación con: imagen de marca verde, satisfacción verde y confianza verde (Tesis de Grado). Chile: Universidad de Chile.

Chen, Y.-S. (2010). The drivers of green brand equity: Green brand image, green satisfaction, and green trust. Journal of Business ethics, 93(2), 307-319.

Bigné, E., Borredá, A., \& Miquel, M. J. (2013). El valor del establecimiento y su relación con la imagen de marca privada: efecto modera- dor del conocimiento de la marca privada como oferta propia del establecimiento. Revista Europea de Dirección y Economía de la Empresa, 22, 1 - 10.

Campano, C., \& Aguirre, M. (2015). Modelo de valor de marca para medios de prensa escritos en un contexto regional. Estudios Gerenciales, 31(135), 150-162.

Barreiro, J., Losada, F., \& Ruzo, E. (2001). Valor de marca, calidad percibida y calidad real: un análisis comparativo del mercado de la leche. Estudios Agrosociales y Pesqueros, 190, $195-221$.

Thompson, I. (2005). La satisfacción del cliente. Rev Med, 1 - 6.

Boubeta, A., García, Alberto, \& Varela, J. (2008). Una aplicación metodológica para el estudio de la imagen de marca de un destino turístico. Pasos. Revista de Turismo y Patrimonio Cultural, 6(1), 1 - 10.

Martínez, E., Montaner, T., \& Pina, J. (2005). Propuesta de medición de la imagen de marca: un análisis aplicado a las extensiones de marca. Revista Asturiana de Economía, 33, 89-112.

Gutiérrez, H., Rodríguez, \& Ignacio. (2010). Los factores estímulo y personales como determinantes de la formación de la imagen de marca de los destinos turísticos: un estudio aplicado a los turistas que visitan un destino vacacional. Cuadernos de Economía y Dirección de la Empresa, 13(43), 37-63.

Schiffman, L. L. (2010). Comportamiento del consumidor. México: Pearson Educación.

Díaz, O., \& Chavez, M. (2015). Las asociaciones" marca producto" $\mathrm{y}^{\prime \prime}$ marca ciudad" como estrategia de" city branding": Una aproximación a los casos de Nueva York, París y Londres. Área Abierta, 15(2), 63 -76.

Rubio-Martín, G., \& Rodríguez, M. (2016). Valoración de marcas a través de modelos financieros. Una aplicación a Melia Hotels International. Cuadernos de Estudios Empresariales, 26, 125-153.

Jiménez, P. (2013). La marca: una visión global. Cont4bl3, 46, 15 - 20.

Cerviño, J., \& Baena, V. (2014). Nuevas dimensiones y problemáticas en el ámbito de la 
creación y gestión de marcas. Cuadernos de Estudios Empresariales, 24, 11 - 50.

Casanovas, M., \& Santandreu, P. (2009). Metodologías para la valoración de empresas hoteleras. Revista de Contabilidad y Dirección, 8, 153 - 172.

Rodríguez, F., \& Brown, F. (2012). El proceso de innovación en el sector de alojamiento turístico mexicano. Estudios y perspectivas en turismo, 21(2), 372-387.

Teece, D., Pisano, G., \& Shuen, A. (1997). Dynamic Capabilities and Strategic. Strategic Management Journal, 18(7), 509-533.

Colmenares, Ó., \& Saavedra, J. (2007). Aproximación metodológica para medir el capital de marca. Caso: cadenas de farmacias en Venezuela. Cuadernos de Administración, 20(33), 203 -228.

Registro Oficial Suplemento 465. (2016). Reglamento de Alojamiento Turístico. Quito: MInisterio de Turismo.

Garolera, J. (1997). Aspectos distintivos del" Brand Equity" en marcas percibidas como locales y como globales (Tesis doctoral). Barcelona: Universidad de Navarra.

Cabrera, S. (septiembre de 2013). La fidelización del cliente en negocios de restauración. Centro de estudios en Diseño y Comunicación, Núm. 45, 155 - 164.

Cabral, M. (2017). El rol de las normas de etiqueta en el Hotel Piscis, Valle de Las Leñas (Mendoza), (Tesis de Grado). Bahía Blanca: Universidad Nacional del Sur.

Zeithaml, V., Bitner, M., \& Dayne, G. (2009). Marketing de servicios (Quinta ed.). México D.F.: McGraw-Hill.

Bassat, L. (2016). El libro rojo de las marcas: Cómo construir marcas de éxito. Debolsillo.

Castillo, J., \& Ortegón, L. (2014). Valor de marca en la industria de las máquinas herramientas en Colombia. Trabajo de grado de la Maestría en Gerencia Estratégica de Mercadeo. Colombia: Politécnico Gran Colombiano.

Levario, G., \& Campos, A. (2018). Elementos del valor de marca y su impacto en la generación de identidad universitaria. Red Internacional de Investigadores en Competitividad, 10(1), 1531-1551.
Valenzuela, M. (2015). La estrategia de marcaciudad en la función de turismo. El Periplo Sustentable, 59-80.

Navas, J. (2015). Reflexiones sobre la identificación y medición del capital intelectual de la empresa. Ciencias Estratégicas, 23(33), 7-13.

Andrade, D. (2016). Estrategias de de marketing digital en la promoción de Marca Ciudad. Escuela de Administración de Negocios, 80, 59-72.

García, \& et al. (2018). Modelo de administración de marcas: un enfoque teórico basado en la teoría general de sistemas. Esic Market Economics and Business Journal, 49(1), 93-117.

Veloutsou, C. (2015). Brand evaluation, satisfaction and trust as predictors of brand loyalty: the mediator-moderator effect of brand relationships. Journal of Consumer Marketing, 32(6), 405-421.

Lieven, T., \& Hildebrand, C. (2016). The Impact of Brand Gender on Brand Equity. International Marketing Review, 33(2), 178-195.

Solsona, J. (2018). Calidad en la gestión de alojamientos turísticos rurales. Gestión Turística, 5, 65-89.

Villarroel, M., \& et al. (2018). Estudio del capital de marca de la marca deportiva de Reebok en el mercado ecuatoriano. Dilemas Contemporáneos: Educación, Política y Valores, 1-13.

López, S. (2017). La notoriedad y calidad percibida de la marca del distribuidor como fuentes del valor de marca para el establecimiento. Tesis de grado. España: Universidad de Extremadura.

Davis, M. (2017). The fundamentals of branding. Switzerland: AVA Publishing.

Kladou, S., \& et al. (2017). The role of brand elements in destination branding. Journal of Destination Marketing \& Management, 6(4), 426-435.

Keller, K. (2016). Reflections on customer-based brand equity: perspectives, progress, and priorities. AMS Review, 6(1), 1-16.

Keller, K. (2017). Measuring Brand Equity. Hanabuch Markenführung, 1-32.

Kotler, P., \& Armstrong, \&. G. (2012). Marketing. Naucalpan de Juárez: Pearson Educación de México, S.A. de C.V. 
Gallart-Camahort, V., Callarisa, L., \& Sánchez, J. (2019). Concepto de marca y sus perspectivas de análisis: una revisión de la literatura. Revista de Marketing Aplicado, 23(1), 41-56.

Berrozpe, A. (2015). La identificación con la marca: conceptualización, caracterización y consecuencias. Opción, 31(2), 144-161.
De la Oliva, E., Gallart, V., \& Fernández, L. (2019). Compromiso activo y valor de marca en el sector del lujo. Redmarka, 23(1), 91-106.

De Oliveira, R. (2019). A Influência das Experiências da Marca no Valor da Marca para o Consumidor (Tesis de Maestria). Lisboa: Instituto Superior de Gestao. 